\title{
NUMERICAL STUDY OF ICE LAYER GROWTH AROUND A VERTICAL TUBE
}

\author{
C. S. Stampa ${ }^{a}$, \\ and A. O. Nieckele N $^{\text {b }}$ \\ ${ }^{a}$ Universidade Federal Fluminense \\ Department of Industrial Metallurgy \\ Av. dos Trabalhadores, 420 \\ 27255-125, Volta Redonda, RJ, Brazil \\ cleyton@metal.eeimvr.uff.br \\ bontifícia Universidade Católica do Rio de \\ Janeiro \\ Department of Mechanical Engineering \\ Rua Marquês de São Vicente, 225 \\ 22453-900, Rio de Janeiro, RJ, Brasil \\ nieckele@mec.puc-rio.br
}

\begin{abstract}
Typical latent heat of fusion storage systems consists of vertical tubes inside a larger container, with phase change material being formed outside the tubes. During the charging stage of the cycle, ice is formed around the exterior of the tubes. Once all water has frozen, the discharging process can begin. This work presents a numerical investigation concerning the growth of an ice layer formed outside a vertical tube, inside an annular cavity. The inner wall of the cavity represents the external wall of the tube, whereas the outer one represents the limit of growth for the formed ice layer. Natural convection plays a significant role during the ice formation, especially due to density inversion behavior with temperature. To be able to control the growth of ice layers inside typical thermal energy storage devices, it is necessary to understand the phenomenum. The problem was solved two-dimensionally, making use of a model based on the finite volume method. The results are presented by means of: streamlines, representing the flow patterns driven by buoyancy forces; isolines of temperature; heat transfer at the inner wall of the cavity and the extraction of the thermal energy stored into the annular region of the cavity.
\end{abstract}

Keywords: ice storage, numerical, performance

\section{NOMENCLATURE}

$b \quad$ depth of the channel

$c p$

$E_{\text {sens }}$

$E_{\text {lat }}$

$f_{s}$

g

$k$

$L$

$L$

$m$

$p$

dimensionless pressure

$q \quad$ local heat flux

$\bar{q} \quad$ average heat flux

rsp constant

$t$ time

$T$ temperature

$\boldsymbol{U}$ liquid velocity vector

$W \quad$ length of the plates

$x, y$ cartesian coordinates

\section{Greek symbols}

$\beta \quad$ exponent of temperature at density

$\Delta h_{\text {lat }} \quad$ latent heat of fusion

$\varepsilon \quad$ volume fraction

$\forall \quad$ volume

$\mu \quad$ dynamic viscosity $\rho \quad$ density

$\begin{array}{ll}\text { Subscripts } \\ C & \text { cold wall } \\ \text { In } & \text { initial } \\ \ell & \text { liquid } \\ m & \text { melting } \\ \text { max } & \text { maximum } \\ r e f & \text { reference } \\ s & \text { solid }\end{array}$

\section{INTRODUCTION}

In typical latent heat of fusion storage systems, which make use of tubular beam, water is utilized as the phase-change material (PCM). This beam consists of tightly spaced small diameter tubes that are arranged in a parallel geometry and are surrounded by water and/or ice in an insulated cylindrical tank. As the tubes are spaced closely together, a crucial problem regarding the performance of such devices arises. There is a reduction in the heat transfer during the charging (ice making) and discharging (ice melting) processes, because the heat transfer area between ice and water is reduced whenever ice formations intersect during charging or water formations intersect during discharging. It is desired to 
determine how to maximize the storage of thermal energy per unit of volume, related to the time response for the processes of recovering and storing energy (Vargas and Bejan, 1995).

During the charging process in the equipments cited above, the liquid phase presents a complex flow structure and temperature distribution, due to the density inversion phenomenon that occurs for the water around $4^{\circ} \mathrm{C}$ (Lin and Nansteel, 1987). This phenomenon drastically affects the thermal exchange between the external wall of the tube and its surroundings. Thus, the shape and the growth velocity of the ice layer around the tube are functions of the flow and temperature fields within the liquid region. The configuration of these fields depends on the initial and boundary conditions considered.

Due to the great importance of the cylindrical geometry in thermal energy storage applications, several works deal with natural convection studies in annular cavities. The performance analyses of latent heat thermal energy storage units (LHTES) have been the task of many works (Lane, 1983; Steiner et al., 1995; Kurklu et al., 1996). However, very few works have considered the transient regime. Stampa and Braga (1996) investigated the phase change process inside a cylindrical tube, while West and Braun (1999) presented a numerical-experimental study regarding the partial charging/discharging processes, with ice making, inside an ice storage tank. Stampa et al. (2001) presented a numerical study of natural convection in vertical annular cavity, considering the density inversion phenomenon. However, they did not consider any ice formation. The study was directed to LHTES using tubular beam, as described before. It was investigated the influence of the multicellular regime in the heat transfer rate, when the superficial area of the inner wall of the cavity is changed. The results were obtained for the conditions of charging (water cooling) and discharging (water heating). Ismail and de Jesus (2001) presented a parametric study of PCM solidification around cylinder for icebank applications.

There are several works that consider the density inversion phenomena at different geometries, such as rectangular cavities (Inaba and Fukuda, 1984; Tong and Koster, 1994), cold water-filled horizontal annular cavities (Vasseur et al., 1983; Ho and Lin, 1990, Yoon et al., 2000), as well as vertical annulus cavities (Lin and Nansteel, 1987; Hirata et al., 2003). One can also find a few works related with freezing of water (Yoon et al., 2001; Cheng and Chang, 2003).

The objective of the present paper is to analyze the transient phenomenon during a specific charging condition, to be able to efficiently control the growth of ice layers in the thermal energy storage devices of the type mentioned before. An annular vertical cavity was employed to represent a typical section of the storage device. The outer cavity wall was insulated, while a fixed cold temperature was imposed at the inner cavity wall. Both upper and lower cavity surfaces were also considered as insulated. The study consists of the numerical investigation regarding the flow structure driven by buoyancy forces, heat transfer at the inner wall of the cavity and removal of heat stored within the annular space.

\section{MATHEMATICAL MODEL}

Figure 1 shows the physical model at some time instant, during which the phase change takes place. The computational domain consists of a vertical annular cavity filled with water as the PCM. The height of the cavity is $L$, the annular gap is $W$ and the inner radius is $R_{i}$. Initially, the system is at a uniform constant temperature, $T_{i n}$, typical to heat storage processes. The top and bottom walls of the cavity, as well as the outer wall are adiabatic. The process begins by imposing a pre-set cold temperature, $T_{c}$, at the inner cavity wall. This temperature is inferior to the temperature of the water melting point $\left(T_{m}=0^{\circ} \mathrm{C}\right)$, in order to allow the extraction of all latent heat stored in the annular region.

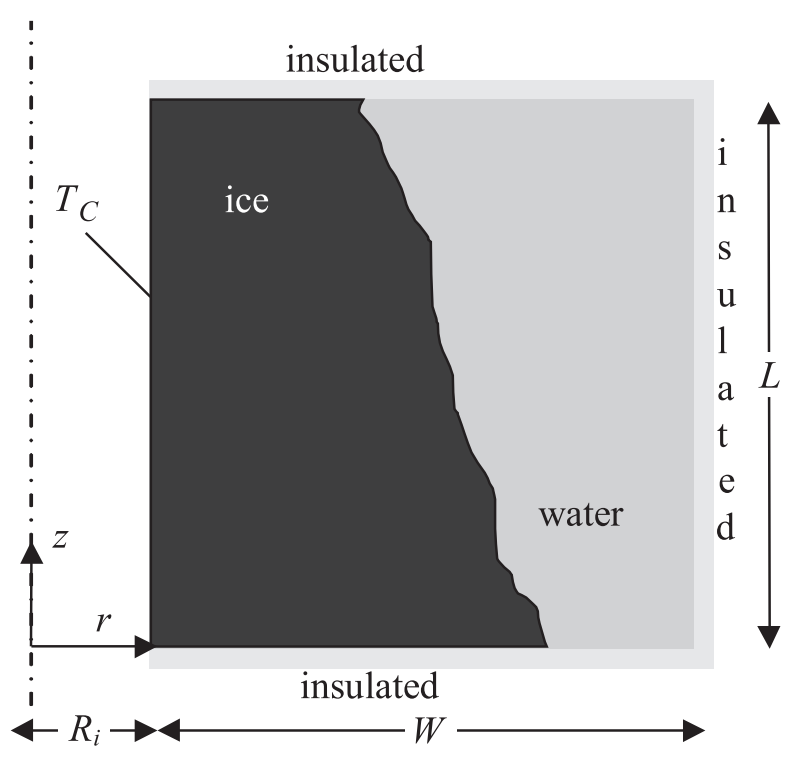

Figure 1. Physical model 
To analyze the current problem, the following assumptions were made: (1) the PCM is a Newtonian fluid with constant properties, except for the liquid density in the buoyancy term, (2) laminar regime, (3) two-dimensional flow, since the buoyancy driven flow may be considered axi-symmetrical for small radius rate (Mcfadden et al., 1984).

The conservation equations of mass and momentum for the liquid phase governing the process are expressed by:

$$
\begin{gathered}
\operatorname{div}\left(\rho_{\ell, \text { ref }} U\right)=0 \\
\frac{\partial\left(\rho_{\ell, \text { ref }} U\right)}{\partial t}+\operatorname{div}\left(\rho_{\ell, \text { ref }} U U\right)= \\
=\operatorname{div}\left(\mu_{\ell} \operatorname{grad} U\right)-\operatorname{grad} p+\rho_{\ell} g
\end{gathered}
$$

The energy conservation equation is solved for both liquid and solid phases, and it can be written as:

$\frac{\partial\left(\left[\rho_{\ell, r e f} c p_{\ell} \varepsilon+\rho_{s} c p_{s}(1-\varepsilon)\right] T\right)}{\partial t}+$

$+\operatorname{div}\left(\rho_{\ell, \text { ref }} c p_{\ell} \varepsilon U T\right)=$

$=\operatorname{div}\left(\left[k_{\ell} \varepsilon+k_{s}(1-\varepsilon)\right] \operatorname{grad} T\right)-\frac{\partial\left(\rho_{s} \varepsilon \Delta h_{\text {lat }}\right)}{\partial t}$

where the thermo-physical properties of the PCM for the liquid $(\ell)$ and solid $(s)$ phases, given by $\rho$, $\mu, k$ and $\mathrm{cp}$ are the density, absolute viscosity, thermal conductivity and specific heat at constant pressure, respectively. $\rho_{\ell, \text { ref }}$ is a reference liquid density, $\boldsymbol{U}$ is the vector velocity, p the pressure, $\boldsymbol{g}$ the gravity vector acceleration, $T$ the temperature and $t$ is the time variable. $\Delta h_{\text {lat }}$ is the latent heat of fusion of the PCM and $\varepsilon$ is the volume fraction, which is defined as:

$$
\varepsilon=\frac{\forall \ell}{\forall}
$$

where $\forall_{\ell}$ and $\forall$ are the liquid and the total volumes, respectively.

According to assumption (1) the liquid density is variable only in the last term of Eq. (2), and it was evaluated by Eq. (5), recommended by Gebhart and Mollendorf (1977), which takes into account the water density inversion phenomenon:

$$
\rho_{\ell}=\rho_{\ell, \max }\left[1-r s p\left|T-T_{\max }\right|^{b}\right]
$$

where $\rho_{\ell, \max }=999.72 \mathrm{~kg} / \mathrm{m}^{3}, \mathrm{rsp}=9.97 \times 10^{-6} \mathrm{~K}^{-\mathrm{b}}$, $\mathrm{T}_{\text {max }}=4.29^{\circ} \mathrm{C}$ and $\mathrm{b}=1.895$.

Initially, all water confined into the cavity is still at temperature $\mathrm{T}_{\text {in }}$, in the liquid phase, for which $\varepsilon=1$. At time equal to zero, the inner wall is cooled and kept at $\mathrm{T}_{\mathrm{c}}$ At the regions where the temperature reaches the ice melting point value, $\mathrm{T}_{\mathrm{m}}\left(0^{\circ} \mathrm{C}\right), \varepsilon$ is set to zero. Note that the last term in the right hand side of Eq. (3) is different from zero only in the regions where the phase change solid-liquid is taking place.

The conservation equation can be written in dimensionless form by the following dimensionless variables:

$$
\begin{array}{r}
U^{*}=\frac{\rho_{\ell, \text { ref } U W}}{\mu_{\ell}} ; P=\frac{p^{*} \rho_{\ell, \text { ref }}}{\left(\mu_{\ell} / W\right)^{2}} ; \theta=\frac{T-T_{c}}{T_{\text {in }}-T_{c}} \\
Z \frac{z}{W} ; \quad R \quad \frac{r}{W} ; \text { Fo } \frac{\mu_{\ell} t}{\rho_{\ell, \text { ref }} W^{2}}
\end{array}
$$

In the above equation, $\mathrm{p}^{*}$ is the modified pressure, which is defined by $p^{*}=p+\rho_{\ell, \max } g \mathrm{z}$. With these variables, the conservation equations become

$$
\operatorname{div}\left(U^{*}\right)=0
$$

$$
\begin{aligned}
& \frac{\partial\left(U^{*}\right)}{\partial F o}+\operatorname{div}\left(U^{*} U^{*}\right)= \\
& =\operatorname{div}\left(\operatorname{grad} U^{*}\right)-\operatorname{grad} P+G r\left|\theta-\theta_{\max }\right|^{b} k \\
& \frac{\partial\left(\left[\varepsilon+\rho^{*} c p^{*}(1-\varepsilon)\right] \theta\right)}{\partial F o}+\operatorname{div}\left(\varepsilon U^{*} \theta\right)= \\
& =\frac{\operatorname{div}\left(\left[\varepsilon+k^{*}(1-\varepsilon)\right] \operatorname{grad} \theta\right)}{P r}- \\
& -\frac{\rho^{*}}{\text { Ste }_{\ell}+\text { Ste }_{s} / c p^{*}} \frac{\partial \varepsilon}{\partial F o}
\end{aligned}
$$

It can be noticed that the problem is governed by the properties parameters: Prandtl number, $\operatorname{Pr}$, densities ratio, $\rho^{*}$, thermal conductivities ratio, $k^{*}$, ratio of specific heat at 
constant pressure, $\mathrm{cp}^{*}$; through the geometric parameters $\mathrm{RR}$ and $\mathrm{AR}$ and the physical parameters: Grashof number, Gr, exponent $\mathrm{b}$ and Stefan number, Ste,

$$
\begin{gathered}
\rho^{*}=\frac{\rho_{s}}{\rho_{\ell, \text { ref }}} \quad ; \quad k^{*}=\frac{k_{s}}{k_{\ell}} \\
c_{p}^{*}=\frac{c p_{s}}{c p_{\ell}} ; \quad \operatorname{Pr}=\frac{\mu_{\ell} c p_{\ell}}{k_{\ell}} \\
R R=\frac{R_{\text {in }}+W}{R_{\text {in }}} ; \quad A R=\frac{L}{W} \\
G r=\frac{\rho_{\ell, \text { max }} g r s p\left(T_{\text {in }}-T_{c}\right)^{b} W^{3}}{\mu_{\ell}^{2} / \rho_{\ell, r e f}} \\
\text { Ste }_{\ell}=\frac{c p_{\ell}\left(T_{\text {in }}-T_{m}\right)}{\Delta h_{\text {lat }}} \\
\text { Ste }_{s}=\frac{c p_{s}\left(T_{m}-T_{c}\right)}{\Delta h_{\text {lat }}}
\end{gathered}
$$

and the initial condition $\theta_{\text {in }}=1$.

\section{NUMERICAL METHOD}

The finite volume method (Patankar, 1980) was selected to solve the coupled set of equations (1) through (3). The Power Law scheme was employed to approximate the diffusive and convective fluxes through the control volume faces. The time marching procedure was treated by using the total implicit scheme. The set of algebraic equations was solved by the TDMA line by line (Patankar, 1980) together with the block correction algorithms (Settari and Aziz, 1973). The pressurevelocity coupling was solved with the SIMPLE algorithm (Patankar, 1980).

A fixed and regular mesh was specified over the whole physical domain. A grid test was performed and the solution was considered independent of the mesh within $1 \%$ with $160 \times 160$ nodal points in the radial and axial directions. The time step adopted was $1 \mathrm{~s}$. The solution was considered converged at each time step, when the residuals of the mass, momentum and energy equations were less than $10^{-6}$, at least for eight consecutive iterations.

\section{RESULTS}

Based on typical latent heat storage units that are submitted to continuous cycles of charge and discharge, the present test case was defined.

The section of the thermal stored device investigated was represented by a cavity with $\mathrm{L}=0.07 \mathrm{~m}, \mathrm{~W}=0.0176 \mathrm{~m}$ and $\mathrm{R}_{\text {in }}=0.0048 \mathrm{~m}$, corresponding to $\mathrm{RR}=4.7$ and $\mathrm{AR}=4$. The charging process was analyzed, starting from an equilibrium situation, where the water was at a uniform temperature $\mathrm{T}_{\text {in }}=40^{\circ} \mathrm{C}$. For $\mathrm{t}>0$, the inner wall was cooled and kept at $\mathrm{T}_{\mathrm{c}}=-10^{\circ} \mathrm{C}$. For this situation, the governing parameters were: $\mathrm{Gr}=5.7 \times 10^{5} ; \mathrm{Ste}_{\ell}=0.504, \mathrm{Ste}_{\mathrm{s}}=0.062, \rho^{*}=1$, $c p^{*}=0.49 ; \mathrm{k}^{*}=1.0$ and $\operatorname{Pr}=8.4$. Calculations were performed until all the liquid phase confined into the cavity was solidified.

The structure of the flow driven by buoyancy forces concerning the charging process of the cavity are presented through streamlines in Fig. 2, at different time instants. The thermal stratification occurring within the PCM can be seen in Fig. 3, through isotherms, for the same time instants as in Fig. 2.

By analyzing Figs. 2 and 3, it can be seen that at $F_{0}=0.58(t=180 \mathrm{~s})$, there is a small layer of ice at the lower region of the inner cylinder, and there is a strong thermally driven clockwise recirculation cell in the pure liquid region. For Fo $=2.0(t=620 \mathrm{~s})$, the average temperature of the liquid region at the bottom of the cavity is smaller than the inversion density temperature for water $\left(\sim 4^{\circ} \mathrm{C}\right)$, what explains the presence of a second counter clockwise rotating cell in this region, which is separated from the upper cell by a maximum density contour. The presence of the secondary cell, together with the growth of the solid layer, decisively affects the thermal exchange performance at the inner wall of the cavity. It is verified that for $\mathrm{Fo}_{\mathrm{o}}=10.4(\mathrm{t}=3220 \mathrm{~s})$, the counter clockwise rotating cell occupies almost the whole remainder liquid region and becomes the dominant cell. This fact should be understood as the result of the global temperature decay within the cavity, which reduces the intensity of the primitive clockwise rotating cell. For Fo $=16.9(t=5220 \mathrm{~s})$, 
it can be observed that the ice has reached the external surface of the annular space and for $F_{0}=23.5(t=7270 \mathrm{~s})$, nearly all the water has solidified. The time interval necessary for the total solidification of the water confined into the cavity corresponds to a maximum Fourier number equal to $\mathrm{Fo}_{\max }=29.7$.

The two cells present inside the cavity have opposite contributions to the ice formation during the charging process. The clockwise cell delays the ice layer growth near the cavity top, because it carries the warmer fluid to the upper region. On the other hand, the counter clockwise rotating cells carries the warmer fluid to the bottom of the cavity, reducing the ice growing velocity in this region. As a result, the ice touches the side wall at $1 / 4$ of the cavity height, leading to a higher inclination on the solid-liquid interface contour.

Figure 4 presents the transient behavior concerning the removal of the thermal energy stored within the annular region. Dimensionless sensible energy $\mathrm{E}_{\text {sens }}$ and latent heat $\mathrm{E}_{\text {lat }}$ were defined based on the maximum stored energy $\mathrm{E}_{\max }$ as:

$$
\begin{array}{r}
E_{\text {sens }}=\frac{\int_{\forall_{\ell}} \rho_{\ell, \text { ref }} c p_{\ell}\left(T_{\text {in }}-T\right) d \forall}{E_{\max }}+ \\
+\quad \frac{\int_{\forall_{s}} \rho_{s} c p_{s}\left(T_{m}-T\right) d \forall}{E_{\max }} \\
E_{\text {lat }}=\frac{\int_{\forall_{\ell, 0^{\circ} C}} \rho_{\ell, \text { ref } \Delta h_{\text {lat }} d \forall}}{E_{\max }}
\end{array}
$$

$$
\begin{aligned}
& E_{\max } \quad m c p_{\ell}\left(\begin{array}{ll}
T_{\text {in }} & T_{m}
\end{array}\right) \\
& c p_{s}\left(\begin{array}{ll}
T_{m} & T_{c}
\end{array}\right) \Delta h_{\text {lat }}
\end{aligned}
$$

where ${ }_{\ell, 0^{o} C}$ represents the volume of material with temperature equal to $0^{\circ} \mathrm{C}$; and $\mathrm{m}$ is the total mass of water within the cavity.

By analyzing Fig. 4, it can be observed that in the beginning of the charging process (ice making), the heat transfer rates are high and a great amount of energy is rapidly extracted from the cavity. As the water solidifies, the sensible heat removed decreases, since there is less liquid water. On the other hand, there is a substantial and continuous increase on the amount of latent heat which is removed. It can also be observed in the graphs presented a variation on the derivatives of each curve, for Fo $=21$, due to the action of the secondary cell.

The average heat flux can be expressed as:

$$
\bar{q}=\frac{1}{L} \int_{0}^{L} \frac{q}{q_{\max }} d z ; \quad q=-k_{s}\left(\frac{\partial T}{\partial r}\right)_{r=R_{i n}}
$$

where q is the local heat flux at the cold wall of the cavity and $\mathrm{q}_{\max }$ is the heat flux at the cold wall for the initial instant of time.

The ice mass fraction can be calculated as:

$$
f_{\text {ice }}=\frac{m_{\text {ice }}}{m}
$$

Figure 5 presents the variation with time of the dimensionless average heat flux variation at the cold wall, as well as the amount of solid formed, i.e., the ice mass fraction. It can be seen a steep variation of the heat flux at the beginning of the process, up to $\mathrm{Fo}_{\mathrm{O}}=2$. After that, there is a strong change in its decay, and a smooth variation can be observed. Note that, as expected, the increase in the amount of ice formed is very similar to the variation of the latent heat with time (Fig. 4). Further, it can be noticed that for $\mathrm{Fo}=$ 2 , the sensible heat starts to decay.

Analyzing Fig. 5, it can also be seen that the change on the slope of the heat flux is related with the increase of the ice mass fraction, due to the enhancement of the thermal resistance imposed by the continuous formation of solid.

\section{CONCLUSIONS}

The solidification phenomenon of water inside a vertical annular cavity, during the charging process (ice making) of the thermal storage device was predicted. The analysis of the flow pattern and temperature distribution, as well as the ice mass fraction distribution with time allows the understanding of this complex phenomenon. The prediction of the removal of the sensible and latent energies stored in the PCM, confined into the annular space, as well as the average heat flux at the cold wall of the cavity can be useful to improve the performance of these types of thermal energy storage devices. 


\section{TECNOLOGIA/TECHNOLOGY}

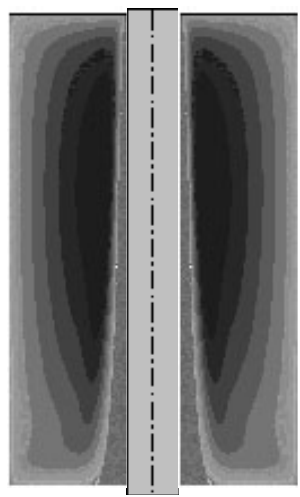

$\mathrm{Fo}=0.58$

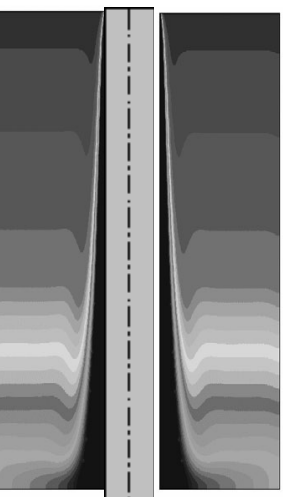

$\mathrm{Fo}=0.58$

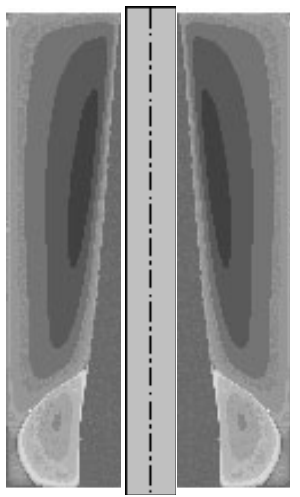

$\mathrm{Fo}_{\mathrm{o}}=2.00$

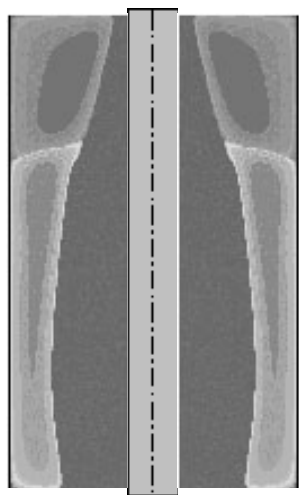

$\mathrm{Fo}=10.4$

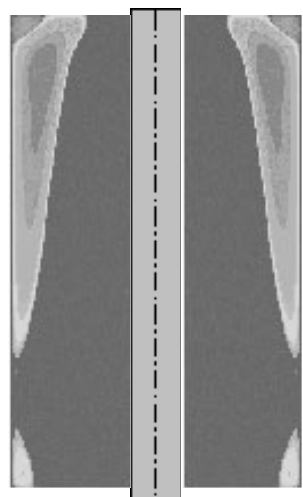

$F_{0}=16.9$

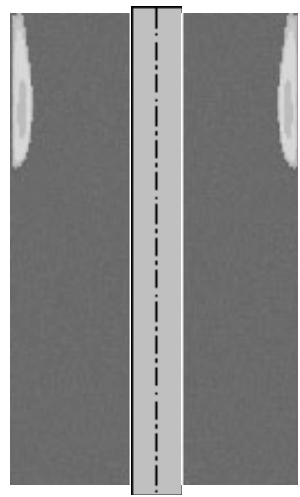

$\mathrm{Fo}=23.5$

Figure 2. Streamlines

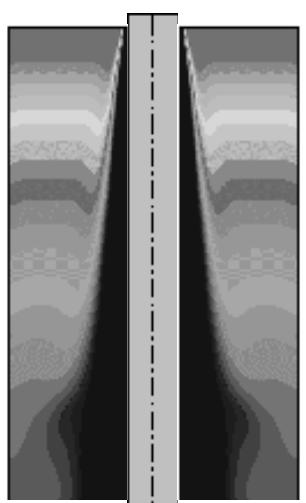

$\mathrm{Fo}_{0}=2.00$

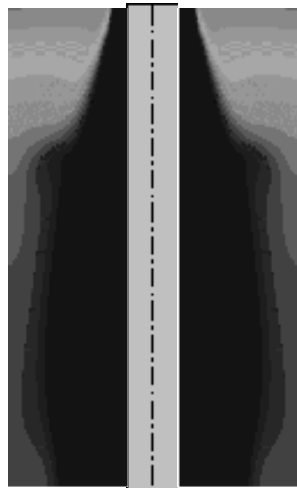

$\mathrm{Fo}=10.4$

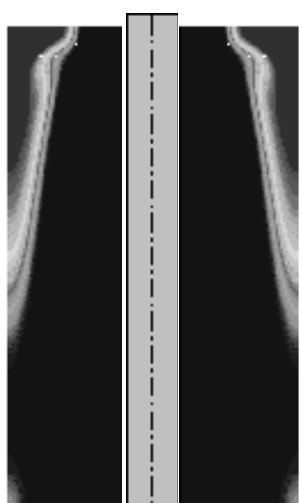

$\mathrm{Fo}=16.9$

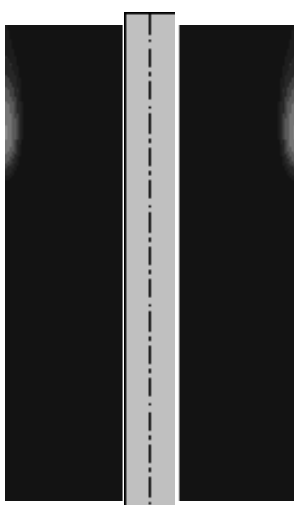

$\mathrm{Fo}=23.5$

Figure 3. Isotherms

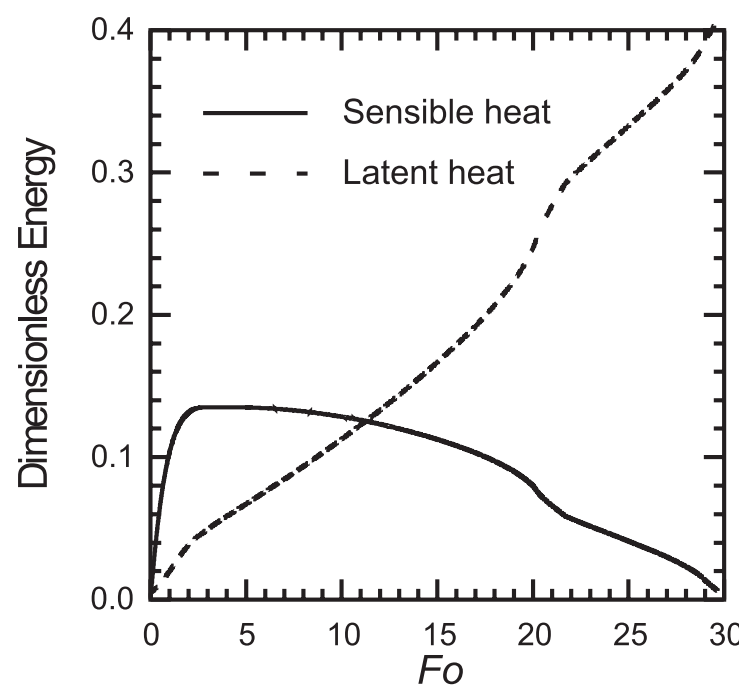

Figure 4. Charging of the annular cavity

Under specific parametric conditions the results showed proportionality relations regarding the amount of sensible and latent energies, which were removed during the period of time necessary to completely charge the cavity. Further, the proportion between the thermal exchange that occurred at the inner wall of the cavity (cold wall) and the amount of formed solid was also analyzed.

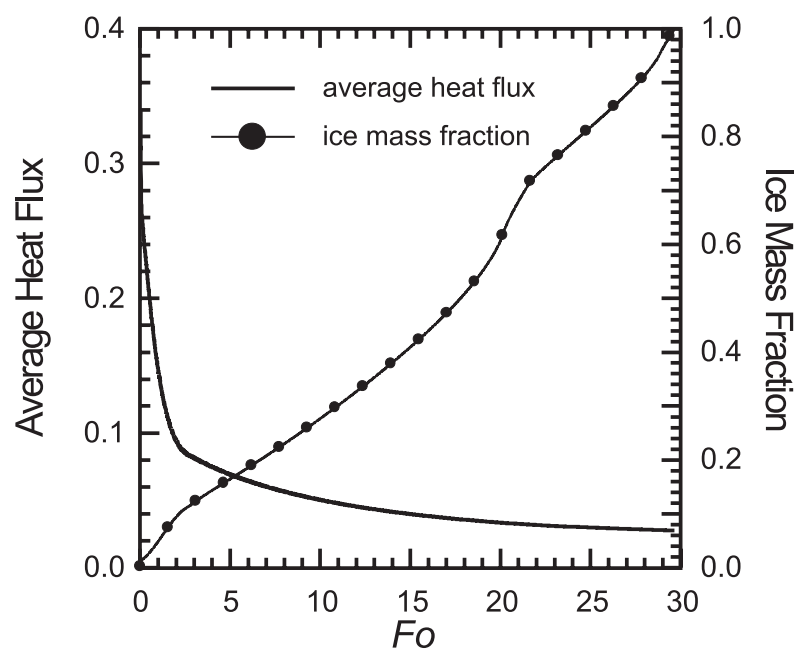

Figure 5. Thermal exchange at the cold wall as a function of the ice formation

This information is conditioned to all the ice that should be formed around the external wall of a typical tube of the thermal energy storage device, but considering no physical contact with other ice layers formed around neighbor tubes. Before analyzing such physical contacts, new numerical studies should be carried out by changing related parameter values. 


\section{REFERENCES}

Cheng, C.-H. and Chang, M.-H., 2003, Shape Identification for Water-ice Interface within the Cylindrical Capsule in Cold Storage System by Inverse Heat Transfer Method, International Journal of Refrigeration, Vol. 26, No. 5, pp. 543-550.

Gebhart, B. and Mollendorf, J. C., 1977, A New Density Relation for Pure and Saline Water, Deep-Sea Research, Vol. 24, pp. 831-848.

Hirata, T., Nishi, T., and Ishikawa, M., 2003, Ice Formation of Aqueous Solution and its Removal Phenomena Around Vertical Cooled Cylinder, International Journal of Refrigeration, Vol. 26, No. 2, pp. 189-196.

Ho, C. J., and Lin, Y. H., 1990, NaturalConvection of Cold Water in a Vertical Annulus with Constant Heat-Flux on the Inner Wall, Journal of Heat Transfer, Vol. 112, pp. 117-123.

Inaba, H., and Fukuda, T., 1984, Natural Convection in an Inclined Square Cavity in Regions of Density Inversion of Water, Journal of Fluid Mechanics, Vol. 142, pp. 363-381.

Ismail, K. A. R., and de Jesus, A. B., 2001, Parametric Study of Solidification of PCM Around a Cylinder for Ice-bank Applications, International Journal of Refrigeration, Vol. 24, No. 8, pp. 809-822.

Kurklu, A., Wheldon, A., and Hadley, P., 1996, Mathematical Modelling of the Thermal Performance of a Phase-Change Material (PCM) Store: Cooling Cycle, Applied-ThermalEngineering, Vol. 16, No. 7, pp. 613-623.

Lane, G. A., 1983, Solar Heat Storage Latent Heat Material, CRC Press, Boca Raton, Vol. 1.

Lin, D., and Nansteel, N. W., 1987, Natural Convection Heat Transfer in a Vertical Annulus Containing Water near the Density Maximum, Journal of Heat Transfer, Vol. 109, pp. 899-905.

Mcfadden, G. B., Coriell, S. R., Boisvert, R. F., and Glicksman, M. E., 1984, Asymmetric Instabilities in Buoyancy-driven Flow in a Tall Vertical Annulus, Physics of Fluids, Vol. 27, pp. 1359-1361.

Patankar, S. V., 1980, Numerical Heat Transfer and Fluid Flow, Hemisphere Publishing, New York.

Settari, A., and Aziz, K., 1973, A Generalization of the Additive Correction Methods for the Iteractive Solution of Matrix Eq., SIAM Journal of Numerical Analysis, Vol. 10, pp. 506-521.
Stampa, C. S., and Braga, S. L., 1996, Estudo da Recuperação do Calor Armazenado em Materiais de Mudança de Fase no Interior de Dutos Cilíndricos, In: VI Encontro Nacional de Ciências Térmicas, Vol. 2, pp. 985-989. (in Portuguese)

Stampa, C. S., Nieckele, A O., and Braga, S. L., 2001, Water Charging and Discharging Processes in a Vertical Annulus Concerning AreaConstrained, Ice-on-Pipe Storage Tanks, In: $2^{\text {nd }}$ International Conference on Computational Heat and Mass Transfer, RJ, RJ, Brazil.

Steiner, -D., Wierse, -M., and Groll, -M., 1995, Development and Investigation of Thermal Energy Storage Systems for the Medium Temperature Range, In: Intersoc Energy Convers Eng Conf., Vol. 2, pp. 193-198.

Tong, W., and Koster, J., 1994, Density Inversion Effect on Transient Natural Convection in a Rectangular Enclosure, International Journal of Heat and Mass Transfer, Vol. 37, pp. 927-938.

Vargas, J. V. C., and Bejan, A., 1995, Fundamentals of Ice Making by Convection Cooling Followed by Contact Melting, International Journal of Heat and Mass Transfer, Vol. 38, No. 15, pp. 2833-2841.

Vasseur, P., Robbilard, L., and Shekar, B. C., 1983, Natural Convection Heat Transfer of Water within a Horizontal Cylindrical Annulus with Density Inversion Effects, Journal of Heat Transfer, Vol. 105, pp. 117-123.

West, J., and Braun, J. E., 1999, Modeling Partial Charging and Discharging of AreaConstrained Ice Storage Tanks, International HVAC\&R, vol. 5, No 3, pp. 209-228.

Yoon, J. I., Kwon, O. K., Moon, C. G., Son, Y. S., Kim J. D., and Kato, T., 2000, Numerical Study on Cooling Phenomenon of Water with Supercooled Region in a Horizontal Circular Cylinder, Numerical Heat Transfer Part A: Applications, Vol. 38, No. 4, pp. 357-376.

Yoon, J. I., Moon, C. G., Kim, E., Son, Y. S., Kim, J. D., Kato, T., 2001, Experimental Study on Freezing of Water with Supercooled Region in a Horizontal Cylinder, Applied Thermal Engineering, Vol. 21, No. 6, pp.657-668. 